\title{
PROSPECTS AND STATUS OF LOW-ASPECT-RATIO TOKA.MAKS
}

\author{
Y-K. M. Peng \\ Oak Ridge National Laboratory \\ P.O. Box 2009-8071 \\ Oak Ridge. Tennessee 37831 \\ (615)576-7476
}

\section{ABSTRACT}

The prospects for the low-aspect-ratio (A) tokamak to fulfill the requirements of viable fusion power plants are considered relative to the present status in data and modeling. Desirable physics and design features for an attractive Blanket Test Facility and power reactors are estimated for low-A tokamaks based on calculations Improved with the latest data from small pioneering experiments. While these experiments have contirmed some of the recent predictions for low-A, they also identify the remaining issues that require verification before reliable projections can be made for these deuteriumtritium applications. The results show that the low-A regime of small size, modest field, and high current offers a path complementary to the standard and high $\mathrm{A}$ tokamaks in developing the fuil potential of fusion power.

\section{INTRODUCTION}

Projectıons for deuterium-tritium ( $D-T$ ) applicatıons of low-aspect-ratio $\left(A \equiv R_{N} / a\right)$ or spherical tokamaks have been improved based on recent high-temperature data from a number of small pioneering experıments such as Smail Tight Aspect Ratio Tokamak (START). 'Helicity Injected Tokamak (HIT), ${ }^{2}$ Current Drive Experıment-Upgrade (CDX-U), ${ }^{3}$ and Tokyo Spheromak-3 (TS-3) converted to tokamak. ${ }^{3.4}$ These projections indicate that plasmas for $\mathrm{A}$ $=1.2$ to 1.3 with $\left(R_{n}+a\right) \leq 1.4 \mathrm{~m}$ and $I_{p}=6$ to $10 \mathrm{MA}$ can be driven to steady state ${ }^{5,6.7}$ and produce high fusion neutron wall loads $W_{L}$ around $1 \mathrm{MW} / \mathrm{m}^{2}$. Such plasmas would permit small nearer-term Blanket Test Facilities $(B T F)^{\circ}$ for testing tull-function blanket modules for fusion. For $A=1.2$. plasma properties were calculated ${ }^{5.8}$ for future power plants that have the potential capability of complementing the best reactors based on the standard or high $A(=2.5$ to +.5$)$ tokamaks in providing economic power.
In the present paper, the requirements for attractive BTF and reactors, and the desirable plasma and design features projected for low-A are identified in Section II. The status of the low-A experimental data relative to these projections and the research issues are presented in Section III. The paper closes with a discussion in Section IV of low-A development steps that can contribute to realizing the full potential of tokamak fusion power.

\section{ECONOMIC FUSION POWER REQUIREMENTS AND LOW-A TOKAMAK FEATURES}

A key motivation for lowering $A$ has been to obtain high beta (hence low external field) and good confinement (hence small plasma size). These together would reduce reactor power source size and capital investment. ${ }^{8}$ The potential benefit of reducing $A$ was already seen in the limited physics indications a decade ago." However. lowA was not pursued at that time because of uncertanties in the method of plasma production.

Since then standard and high A tokamak research has made great progress in data, interpretation. modeling, and the awareness of requirements for producing economic power. These stringent requirements are listed below in qualitative terms together with the calculated, desirable. low-A tokamak physics and engineenng features:

- Low power source equipment cost - small plasma size with high beta and good confinement: The magnitude of the plasma shaping factor $S\left(\equiv I_{p} q / a B_{n 0}\right)$ has been measured in DIII- $D^{10}$ and shown to be a good indicator for the best $\beta \tau_{E}$ values obtained. Free-boundary magnetohydrodynamic (MHD) equilibria with "natural" elongations without using shaping poloidal field coils (PFCs) are calculated as A is reduced from 2.5 to 1.2. The results are summarized in Table I and Figure 1. 


\section{DISCLAIMER}

Portions of this document may be illegible in electronic image products. Images are produced from the best available original document. 
TABLE I. ASPECT RATIO AND q DEPENDENCES OF VATURALLY ELONGATED PLASMAS

\begin{tabular}{|c|c|c|c|c|}
\hline Ispect ratio $\mathrm{A}$ & 2.5 & 1.4 & 1.2 & 1.2 \\
\hline Edge sarety iactor $\mathrm{q}_{v}$ & 2.7 & 6.8 & 17.1 & 21.8 \\
\hline Axis sarety factor $q_{0}$ & 1.0 & 1.0 & 1.0 & +.7 \\
\hline$"$ Natural" elongation $\mathrm{k}$ & 1.0 & 1.5 & 2.0 & 2.3 \\
\hline$\left.\beta_{1}\left(\equiv 2 \mu_{1}\right)(p) / B_{0}^{-}\right)^{2}$ & 0.8 & 0.6 & 9.6 & 1.1 \\
\hline $3_{v_{i}}\left(\equiv\left\langle\beta_{i}\right) a B_{k} / I_{p}\right)$ & 0.04 & 0.04 & 0.04 & 0.12 \\
\hline$\left.\beta_{1}\right\rangle\left(\equiv 2 \mu_{n}\langle p\rangle / B_{m}{ }^{-}\right)$ & 0.04 & 0.12 & 0.21 & 0.92 \\
\hline $\mathrm{S}\left(\mathrm{MA} \cdot \mathrm{m}^{-1} \cdot \mathrm{T}^{-1}\right)$ & 2.7 & 20 & 89 & 174 \\
\hline Field uttlization $I_{\rho} / I_{\mathrm{rfc}}$ & 0.08 & 0.42 & 0.87 & 1.3 \\
\hline Diverted SOL $\Delta_{\text {div }} / \Delta_{\text {SOL }}{ }^{b}$ & 0 & -0.6 & -0.9 & $-1) .9$ \\
\hline
\end{tabular}

" $\mathrm{B}_{\mathrm{p}}=$ edge circumference-average of poloidal field.

" assuming $\Delta_{\mathrm{SOL}} \sim 0.1 \mathrm{a}$ for low-A cases.

It is seen that $S$ increases strongly as $A$ is reduced. especially from low (1.4) to very low (1.2) values as $K$ also increases to about 2 . Reducing the plasma internal inductance (as $q_{d} / q_{y}$ is increased) at very low-A further doubles $S$ and increases $K$ to 2.3. The average toroidal beta $\left\langle\beta_{t}\right\rangle$ for $A=1.2$ can reach high values ${ }^{7}$ for the first regime $\left(q_{0}=1.0\right)$ and very high values ${ }^{3}$ for the second regime $\left(q_{n}=4.7\right)$ of stability for ballooning modes.

Assuming the first-regime values, a device with $R_{n} \approx$ $0.8 \mathrm{~m}$ and $\mathrm{B}_{\mathrm{m}}=2 \mathrm{~T}$ would permit $\mathrm{I}_{\mathrm{p}} \approx 9 \mathrm{MA}$ and $\left\langle\beta_{\rangle}\right\rangle \mathrm{B}_{\mathrm{t}}{ }^{2}-$ $100 \% \mathrm{~T}^{2}$. This gives a plasma pressure about twice that in the Joint European Torus (JET) for $B_{10}=3 \mathrm{~T}$ and $\langle\beta\rangle=$ $5 \%$. Such a plasma would permit an attractive BTF candidate $^{5.6}$ that produces the JET-level D-T physics performance of $Q-1$, while producing fusion powers -20 to $30 \mathrm{MW}$ and $\mathrm{W}_{\mathrm{L}}-1 \mathrm{MW} / \mathrm{m}^{2}$. Estimates of the reactor parameters ${ }^{3}$ using a systems code (an ST version of SuperCode $\left.{ }^{\prime \prime}\right)$ assuming the second-regime indicate $\left(R_{n}+a\right)$ $\approx 5.4 \mathrm{~m}$ and $W_{\mathrm{L}} \approx 6 \mathrm{MW} / \mathrm{m}^{2}$ for producing $1000 \mathrm{MW}$ in net electricity. The power source equipment cost is estimated to be about one-half of that based on high $A$ advanced tokamak physics. Example parameters for the low-A BTF and reactor are provided in Table II.

- Reliable operation - freedom from plasma vertical instability and current-terminating disruptions: The vertical displacement event (VDE) and the subsequent disruption ${ }^{12}$ of the plasma current must be eliminated or controlled before a reliable plasma core can be obtained for future tokamak reactors. ${ }^{13}$ Early calculations ${ }^{9}$ and Figure I show that low-A plasmas can be strongly elongated using vertıcal fields with slightly negative field decay indices. Such low-A plasmas are theretore expected to be vertically stable without requiring teedback control.
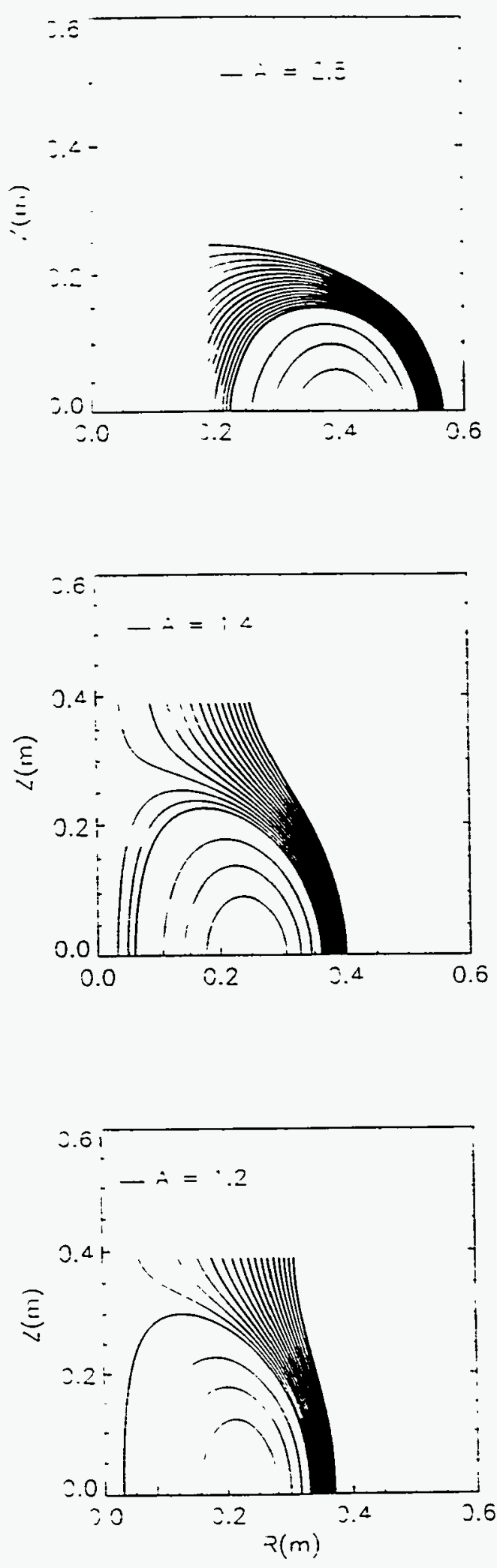

Figure 1. Free-boundary equilibria for $\mathrm{A}=2.5,1.4$, and 1.2 using only two parrs of outboard PFCs. 
TABLE II. REPRESENTATIVE PARAMETERS FOR LOW-A BTF AND REACTORS

\begin{tabular}{|c|c|c|}
\hline Device Parameters & BTF & Reactor \\
\hline Plasma size $(R, r a)(m)$ & 1.4 & 5.4 \\
\hline tspect rallo $\mathrm{A}$ & 1.25 & 1.2 \\
\hline Torordal field at $R_{n}(T)$ & 2.0 & 2.4 \\
\hline Plasma current $I_{g}(\mathrm{MA})$ & 9.4 & 43.0 \\
\hline H-factor (ITER-power) & 2.5 & $\therefore .4$ \\
\hline Normalızed toroıdal beta $\beta_{\mathrm{N}_{\mathrm{t}}}$ & 3.5 & 5.8 \\
\hline A verage torordal beta $\left\langle\beta_{\mathrm{l}}\right\rangle$ & 0.24 & 0.44 \\
\hline Fusion power (MW) & 32 & 2770 \\
\hline Drive power (MW) & 19 & 54 \\
\hline Fusion neutron wall load $\left(\mathrm{MW} / \mathrm{m}^{-}\right)$ & 1.0 & 6.0 \\
\hline
\end{tabular}

- Low recirculating power - large plasma pressureJriven current fraction. low noninductive seed current drive. and low resistive power in normal conducting magnets: Since $I_{p} I_{\text {tfc }}=S / 5 q_{y} A$, we find $I_{p} / I_{\text {ffic }}=3 / 2$ for the fourth case shown in Table I. The low-A power reactor of Table II would have $I_{\text {Ifc }} \approx 29 \mathrm{MA}$. The resistive power required to drive a steady state toroidal field coil (TFC) with a tapered single-turn copper center leg ${ }^{13}$ is estimated to be about $150 \mathrm{MW} .^{8}$ Such plasmas were also calculated $^{8.14}$ to have the potential for a pressure-driven current fraction up to $90 \%$ at the maximum stable beta. Using current drive by MV-level neutral beams, the required power is estimated to be about 50 to $100 \mathrm{MW}$ deposited. The total recirculating power for this power plant is then estimated to about $400 \mathrm{MW}$. This may seem high. However, since the power core equipment cost is relatively low, the cost of electricity (COE) still becomes about $20 \%$ lower than the best reactor COE based on the high $\mathrm{A}$ advanced physics tokamak.

- Sustained power and particle handling, impurity control - diverted and thick plasma scrape-off layer (SOL) and techniques to disperse exhaust heat over large surface areas: As seen in Figure I, an increasing fraction of the SOL becomes diverted naturally without using divertor colls as A is reduced toward unity. An MHD instability model ${ }^{\circ}$ has been suggested recently to provide a possible mechanısm to maintain a thick SOL in low-A tokamaks. This model suggests that the low-A reactor plasma would have a thick SOL $(\approx 30 \mathrm{~cm})$, about six times that projected for the best high $A$ tokamak reactor. Such a thick SOL would become over $90 \%$ diverted for $A=1.2$. which would ease the power loading on the inboard limiters that protect the inner leg of the TFC. A divertor channel of about $2 \mathrm{~m}$ in length. similar to that assumed in ITER. ${ }^{15}$ :vould be provided for future low-A tokamak reactors.
- Adequate maintanability - remotely replaceable reactor power source components permitting scheduled maintenance shutdown in about 3 months biannually: Because of the large $S$ values. relatıvely small fields are expected for future low-A devices (see Table II). A singleturn center leg for the TFC can become teastble for future D-T-fueled devices." Remote maintenance and replacement of all reactor core components in this case becomes more practucal than standard tokamaks with superconducting TFCs. Reactor components that will require regular replacement include the TFC center leg, divertors, first wall, and blankets. The natural divertors permit a simplified PFC configuration. further improving mantainability.

- Potential to permit environmentally clean power using only low activation materials: Assuming the avaliability of proper low activation materials for all the torus components. the copper center leg becomes the only remaining source of significant actuvation in D-T-fueled devices. A copper center leg would be acceptable for devices otherwise using standard materials.

- Low power required for startup - easy noninductive current initiation and ramp-up and modest heating to achieve fusion burn: The inboard solenoid must be eliminated to permit very low-A plasmas, rendering noninductive initiation and ramp-up a unique key issue. The auxiliary heating power would be considered modest if it is comparable to the power required for current drive.

These reactor requirements and desirable low-A features are summarized in Table III. Technical advances. such as very high efficiencies for conversion of thermal energy to electricity. low-cost high-field or hightemperature superconductung magnets. and low-cost strong matenals are not included because they apply equally to all tokamaks.

\section{PRESENT EXPERIMENT AND MODELING STATUS}

Low-A tokamak research began about 7 to 8 years ago. The devices since then are summarized in Table IV. Results for high plasma temperatures were first obtained in START. ${ }^{1}$ followed possibly by HIT ${ }^{2}$ and CDX-U. ${ }^{3}$ Data so far have been limited to ohmic plasmas with $I_{p}$ up to $250 \mathrm{kA}$ (for 5 to $10 \mathrm{~ms}$ ), $R_{0}$ up to $30 \mathrm{~cm}$, and plasma tlattop durations up to $20 \mathrm{~ms}$ ( for $I_{p}$ up to $150 \mathrm{kA}$ ). The toroidal field $B_{n}$ applied at the major radius have been up to about $0.5 \mathrm{~T}$. The best data ${ }^{1}$ have been characterized by $\mathrm{T}_{\mathrm{e} 0} \leq 1 \mathrm{keV}, \mathrm{n}_{\mathrm{e} 0} \leq 2.5 \times 10^{14} \mathrm{~cm}^{-3}$. and $\mathrm{T}_{10} \leq 0.2 \mathrm{keV}$. 
־ALE III. REQLIRE.MENTS. DESIRABLE FEATLRES. STATLS. AND PROJECTIONS FOR LOW-A TOKA.MAKS

\begin{tabular}{|c|c|c|c|}
\hline $\begin{array}{l}\text { Requirements for } \\
\text { Viable Reactors }\end{array}$ & $\begin{array}{l}\text { Desirable Physics and } \\
\text { Design Features }\end{array}$ & $\begin{array}{c}\text { Present } \\
\text { Low-A Data }\end{array}$ & $\begin{array}{c}\text { Reactor } \\
\text { Projections }\end{array}$ \\
\hline Luw power source equipment cost & 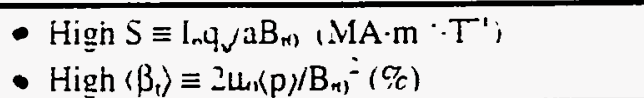 & $\begin{array}{l}20 \\
2\end{array}$ & $\begin{array}{l}200 \\
100\end{array}$ \\
\hline Reliable operamon & $\begin{array}{l}\text { - Vertical stability for high bla } \\
\text { - Disruption-tree operation }\end{array}$ & $\begin{array}{c}\leq 4 \\
\text { Ohmic plasma }\end{array}$ & $\begin{array}{c}\leq 3 \\
\left.\text { High } S . \beta_{1}\right\rangle\end{array}$ \\
\hline Luw rectrculatme power & 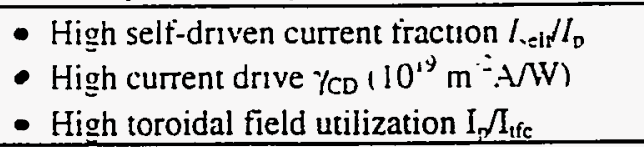 & $\begin{array}{c}10.2 \\
-4 \\
3 \\
\end{array}$ & $\begin{array}{l}11.95 \\
10.3 \\
\leq 3 \\
\end{array}$ \\
\hline $\begin{array}{l}\text { Sustainea power and partucle } \\
\text { landline, impurin control }\end{array}$ & $\begin{array}{l}\text { - Thick } \Delta_{\text {sol }}(\mathrm{cm}) \\
\text { - Long divertor channel }(\mathrm{m})\end{array}$ & $\begin{array}{c}3 \\
0.5\end{array}$ & $\begin{array}{l}30 \\
2.0\end{array}$ \\
\hline tdequate maintainability & $\begin{array}{l}\text { - Demountable jointed TFC } \\
\text { - Simple PFC (natural divertor) } \\
\end{array}$ & $\begin{array}{l}\text { Yes } \\
\text { Yes } \\
\end{array}$ & $\begin{array}{l}\text { Single-turn } \\
\text { Yes } \\
\end{array}$ \\
\hline $\begin{array}{l}\text { Potential to permut environmentally } \\
\text { clean power }\end{array}$ & $\begin{array}{l}\text { - Can use "advanced" materials. except the } \\
\text { copper center leg }\end{array}$ & Cupper TFC & $\begin{array}{l}\text { Copper or other } \\
\text { matenal }\end{array}$ \\
\hline Low cost for power startup & $\begin{array}{l}\text { - Permit easy noninductıve current } \\
\text { Inituation and ramp-up } \\
\text { - Require only modest auxiliary heatıng }\end{array}$ & $\begin{array}{l}\text { HI to } 250 \mathrm{kA} \\
{ }_{-}\end{array}$ & $\begin{array}{l}\text { To several MA } \\
P_{\text {heaung }} \leq P_{C D}\end{array}$ \\
\hline
\end{tabular}

* Not yet tested for low-A.

TABLE IV. REPRESENTATIVE PARAMETERS OF RECENT AND PRESENT LOW-A TOKAMAK EXPERIMENTS

\begin{tabular}{|c|c|c|c|c|c|c|c|}
\hline Device Name & $\mathrm{R}_{\mathrm{n}}(\mathbf{c m})$ & $\mathbf{a}(\mathrm{cm})$ & $A=R_{0} / a$ & $\mathrm{I}_{\mathrm{p}}(\mathrm{kA})$ & $t_{\text {puise }}(s)$ & $B_{10}(k G)$ & $\mathrm{T}_{\mathrm{e} 0}(\mathrm{eV})$ \\
\hline $\mathrm{HSE}+\operatorname{rod}^{16}$ (FRG. 1987) & 7 & 6 & 1.1 & 100 & 0.06 & 1.1 & 20 \\
\hline ROTOMAK + TF ${ }^{17}$ (Australia. 1987) & 7 & 6 & 1.1 & 3 & 20 & 0.2 & 12 \\
\hline FBX II $^{18}$ (Japan. 1990) & 47 & 33 & 1.4 & 100 & 2 & 5 & 300 \\
\hline SPHEX Tokamak ${ }^{19}$ (UK. 1991) & 23 & 22 & 1.05 & 200 & 0.7 & 4.5 & 30 \\
\hline START'(UK. 1991) & 30 & 25 & 1.3 & 250 & 40 & 5 & 500 \\
\hline TS-3, low-A $\mathrm{A}^{3.20}$ (Japan, 1991) & 20 & 14 & 1.5 & 50 & 2 & 3 & 40 \\
\hline TS-3. ultra-low- $A^{\text {j.20 }}$ (Japan. 1993) & 20 & 18 & 1.05 & 50 & 0.1 & 1.5 & 20 \\
\hline HIT' $^{-}$(USA. 1994) & i) & 20 & 1.5 & 250 & 10 & +.6 & 100 \\
\hline CDX-Uं (USA. 1994) & 32 & 20 & 1.6 & 50 & 6 & 1.0 & 100 \\
\hline
\end{tabular}

These results in general are very modest relative to the projections desired for future D-T applications. However. several reactor requirements have nevertheless already been confirmed. These are included in Table III and Jiscussed below.

- Low power source equipment cost - The magnitude of the plasma shapıng factor $S$ reached about $20 \mathrm{MA} \cdot \mathrm{m}^{-1} \cdot \mathrm{T}^{-1}$ in START for $A=1.4$, about twice the best $S$ values sbtained so far in DIII-D. ${ }^{11}$ Vertically stable. very high $x$ $i=3$ to 4$)$ plasmas with hollow current protiles have been seen for short durations immediately following inductive iartup in START.' Equilibrium modeling of these plasmas have provided confidence that the high $S$ and $\kappa$ values of Table I are teasible for very low A tokamaks.

Reliable operation - The START plasmas have been found to be vertically stable for natural elongations up to 4. In addition. the ohmic plasma in START has not sutfered any current-terminating disruptions for $A \leq 1.8$ for about 20.000 shots. though internal MHD activities and reconnection events have been observed regularly. ${ }^{-1}$ While this is encouraging, the mechanisms for such resilience are not understood at present. Whether this can be maintained for high $S$ high $\left\langle\beta_{1}\right\rangle$ low-A plasmas remains to be tested in collisionless high-temperature plasmas. 
- Low recirculating power - The rraction or pressureJriven currents in START has been estimated to be up to 1. 2 so iar. Intial theoretical indications are that the neoclassical model will require adjustment for very low-A. and enhancement for the bootstrap current ${ }^{2}$ and reductions in neoclassical ion diffusion coefficient $"$ have been -uggested. Tests in collisionless plasmas will therefore be required. There are currently no data for current drive in high temperature low-A plasmas. The ability for the plasma to permit high values of $I_{p} / I_{\text {tic }}$ (up to $f$ ) without tult or shift instabilities has been verified recently in TS-3 in relatıvely collisional plasmas. ${ }^{320}$ Tests in collisionless plasmas will be required before adequate contidence in these issues can be established.

- Sustained power and particle hanaling. impurtry control - A thick outboard plasma SOL. about 3 to 5 times the predictions of conventional theory, with relatively high alectron temperatures $(-50 \mathrm{eV})$ and large fluctuations has heen measured ${ }^{-1}$ in START. This is so tar consistent with the condition of marginal MHD stability for the SOL. ${ }^{5}$ Further, the SOL in START is largely ( $-65 \%)$ diverted without using divertor coils. The latter result is consistent with MHD equilibrium calculations. ${ }^{3}$ A natural divertor channel of about $0.5 \mathrm{~m}$ in length is already avallable in START. More detailed measurements for hightemperature SOL plasmas in low-A tokamaks will be needed before projections to future large devices can be made with contidence.

- Adequate maintainability - All small low-A tokamak experiments so far (see Table IV) have normal conducting TFCs with demountable joints. Experience in START 1)peration and modifications have indicated that such an .rrangement is tlexible and provides superior accessibility to the plasma chamber. Concepts recently suggested ${ }^{i 2 . i 3}$ for future low-A tokamak reactors have assumed TFCs with a single-turn center leg with minimal or no shielding. Design, construction, and operation of a small BTF would provide valuable experience in remote mantenance of $D$ T-fueled low-A tokamaks.

- Potential to permit environmentally clean power The activation and damage of unshielded copper in the fusion environment needs to be studied before its advantages and limitations for low-A D-T-fueled tokamaks can be understood. Alternative conductors (to copper) should also be examined.

- Low power required for startup - HIT has recently proven the feasıbility of initiating low-A plasma currents efficiently for up to $250 \mathrm{kA}$ using axisymmetric coaxial electrodes." This method for plasma startup deserves much study to permit implementation in larger collisionless piasmas with conridence. Other possible uptions include injections of electron cyclotron (EC) and lower hybrid (LH) waves. which have had some successes in standard tokamaks iup to $100 \mathrm{kA}$ for initiation and up to $2 \mathrm{MA}$ for ramp-up/ at low densitues. The tecinnique of inductioncompression utulized successtully in START ${ }^{i}$ can be used If space outboard to the plasma can be made avallable in future $\mathrm{D}-\mathrm{T}$ devices.

\section{DISCUSSION}

As can be seen in Table III. recent experimental results have confirmed high natural plasma elongation: vertucal stability; natural divertor using relatıvely sımple PFCs: and high toroidal field uttlization $\left(\mathrm{I}_{\mathrm{p}} / \mathrm{I}_{\mathrm{tfc}}\right)$. Jointed demountable TFC has been commonly used. However. there remain many features where substantial progress is needed for economically compettive power plants, and to a lesser degree. for the BTF. These include high shape factor S: order-unıty stability beta limıts and pressuredriven current traction: disruption-tree operation for high $S$ and high beta: efficient current drive: thick SOL with long divertor channels for high $S$ and high beta: noninductive initiation and ramp-up of high plasma currents; and modest auxiliary heating power for fusion burn. Alternatives to the center leg copper with improved radiation damage and activation properties may require detailed study.

These features need to be tested in collisionless plasmas with $I_{p}$ at the mega-ampere level, requiring about twice the linear size of the present experiments. ${ }^{\text {is }}$ Figure 2 plots the plasma currents and the aspect ratios for such experimental tests relative to examples of the present lowA experiments. the standard and high $A$ experiments, and the projected non- D-T and D-T Jevices.

In the space of the overall plasma size $2\left(R_{n}+a\right)$ and the average fusion neutron wall load we plot in Figure 3 the low-A mega-ampere tests, BTF, and power plant, together with the standard $A$ and advanced physics high $A$ tokamaks (TFTR. JET. ITER. TPX and power plant). It is seen that the low-A tokamak introduces the possibility of using relatively small size plasmas in developing economically compettive fusion power. The utılization of such plasmas. If verified for the collisionless regime. will enhance the full potential of tokamak fusion power.

\section{ACKNOWLEDGMENT}

The author is indebred to D. Strickler and J. Galambos who provided some of the calculations presented in this paper. He has benefited much from discussion with A. Sykes. D. Robinson. W. Morrss. J Hugill. M. Walsh. R. Goldston. S. Kaye. M. Ono. M Yamada. R. Stambaugh. A. Wootton, R. Blanken, and S. Berk. This work is 


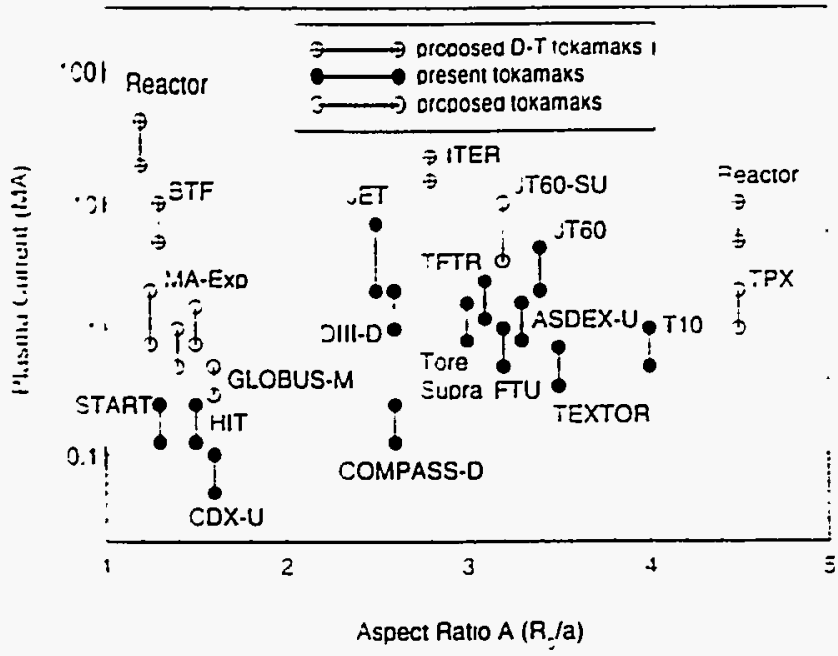

Figure 2. Plasma currents and aspect ratios for present. proposed non-D-T and D-T tokamaks.

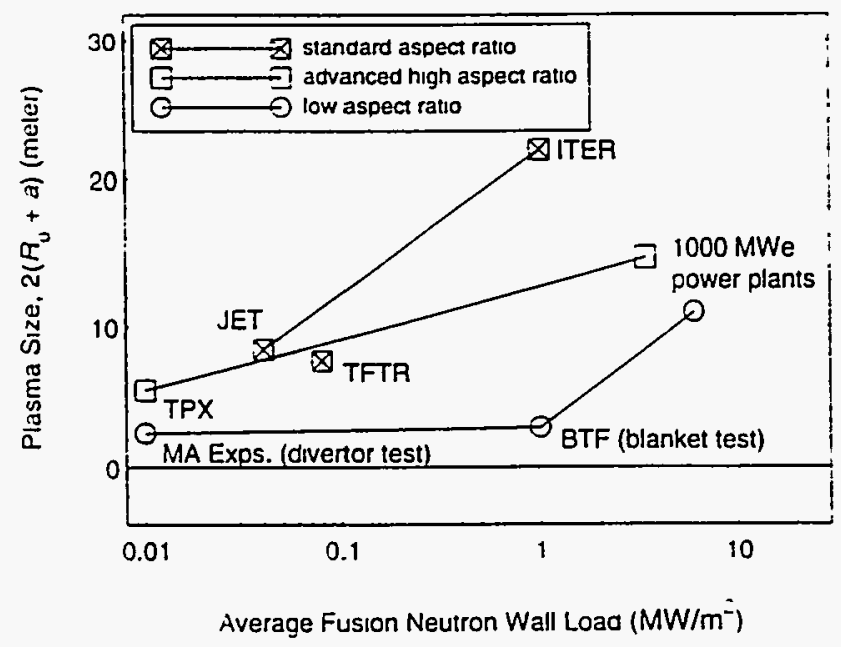

Figure 3. Overall plasma size $2\left(R_{n}+a\right)$ and average neutron wall load for standard aspect ratio. advanced high uspect ratio. and low aspect ratio tokamaks.

sponsored by the U.S. Department of Energy under contract DE-AC05-84OR21400.

\section{REFERENCES}

1. Sykes et al. Nuclear Fusion. 32.694 (1992): A. Sykes et al.. Plasma Phys. and Controlled Fusion. 35. 1051 (1993).

2. B. A. Nelson et al.. Phys. Rev. Lett. 72.3666 (1994): T. R. Jarboe et al.. IAEA-CN-60/A-5-II-6-1(R). to appear in Plasma Phys. Controlled Nuclear Fusion Research 1994. LAEA. Vienna. 1995.
¿. M. Ono et di.. Plasma Physics ana Controlled Vuclear Fusion Research 1992. Vol. 1. p. 693 (IAEA. Vienna. 1993): Y. S. Hwang et al. and A. Morta et al.. IAEA-CN-60/A-5-II-6-2(R). to appear in Plasma Phvs. Controlled Vuclear Fusion Research 1994. I.AEA. Vienna. 1995.

4. Y. Ono et al.. Phys. Fluids B. 5.3691 (1993).

5. R. Buttery et al.. IAEA-CN-60/F-I-3-l(R), to appear in Plasma Phvs. Controlled vuclear Fusion Researci 1994. LAEA. Vienna. 1995.

6. M. A. Abdou et al.. IAEA-CN-60/F-2-II-6-I(R), to sppear in Plasma Phys. Controlled Nuclear Fusion Research 1994. IAEA. Vienna. 1995.

7 . D. C. Robinson. paper 16-02, this conterence.

8. Y-K. M. Peng et al.. IAEA-CN-60/F-I-3-2(R). to appear in Plasma Phys. Controlled Vuclear Fusion Research 1994. IAEA. Vienna. 1995.

9. Y-K. M. Peng, D. J. Strickler. Nuclear Fusion. 26. 576 (1986).

10. E. A. Lazarus et al.. IAEA-CN-60/A-I-5-1. to appear in Plasma Phys. Controlled Nuclear Fusion Research 1994. IAEA, Vienna. 1995.

11. S. W. Haney et al.. Fusion Technology, 21. 1749 (I992).

12. M. A. Pick et al., Fusion Engineering (Proc. 1tth Symp. San diego, CA. 1991) Vol. 1. 187 (IEEE. New York. 1992).

13. Y-K. M. Peng and J. B. Hicks, Fusion Technology 1990, 2, 1287 (1991).

14. T. C. Hender et al., Plasma Phys. Controlled Nuclear Fusion Research 1992. Vol. 3. p. 399. IAEA, Vienna. 1993.

15. P-H. Rebut, "Issue in the Development of Fusion Reactors." paper S-1, this conference.

16. H. Bruhns et al.. Nuclear Fusion. 27. 769 (1987).

17. G. A. Collins et al.. vuclear Fusion. 28. 255 (1988).

18. M. Irie et al.. Proc. 17th EPS Conf. Controlled Fusion and Plasma Physics, Amsterdam. 1990. Part II. p. 245. European Physical Society (1990).

19. K. Browning et al., Phys. Rev. Lett., 68. 1722 (1992).

20. A. Morita. Ph.D. Thesis. to be published.

21. M. Gryaznevich. et al.. Proc. 20th EPS Cont. Controlled Fusion and Plasma Physics. Lisbon. Vol. l. p. 58 (1993).

22. K. C. Shaing. et al.. submitted to Phis. Fluids $B$.

23. D. C. Robinson, et al., Int. Center of Plasma Phys.. India. Vol. I. p. 25 (1989).

24. K. Erents et al.. paper presented at 21st EPS Conf. Controlled Fusion and Plasma Phys.. Montpellier. 1994.

25. Y-K. M. Peng, et al.. "Summary of Workshop on Establishing the Physics Basis for Compact Toroldal Reactors. Oak Ridge. July 19-21. 1994. to be published. 


\section{DISCLAIMER}

This report was prepared as an account of work sponsored by an agency of the United States Government. Neither the United States Government nor any agency thereof, nor any of their employees, makes any warranty, express or implied, or assumes any legal liability or responsibility for the accuracy, completeness, or usefulness of any information, apparatus, product, or process disclosed, or represents that its use would not infringe privately owned rights. Reference herein to any specific commercial product, process, or service by trade name, tràdemark, manufacturer, or otherwise does not necessarily constitute or imply its endorsement, recommendation, or favoring by the United States Government or any agency thereof. The views and opinions of authors expressed herein do not necessarily state or reflect those of the United States Government or any agency thereof. 